\title{
The effect of adding silica to zirconia to counteract zirconia's tendency to degrade at low temperatures
}

\author{
Takashi NAKAMURA ${ }^{1}$, Hirofumi USAMI ${ }^{1}$, Hiroshi OHNISHI², Miyuki TAKEUCHI², Hisataka NISHIDA ${ }^{3}$, Tohru SEKINO ${ }^{4}$ \\ and Hirofumi YATANI ${ }^{1}$ \\ ${ }^{1}$ Department of Fixed Prosthodontics, Osaka University Graduate School of Dentistry, 1-8 Yamadaoka, Suita, Osaka 565-0871, Japan \\ ${ }^{2}$ Nikkato Corporation, 3-2-24 Orino-cho, Sakai, Osaka 590-0001, Japan \\ ${ }^{3}$ Department of Operative Dentistry, Osaka Dental University, 8-1 Kuzuhahanazono-cho, Osaka 573-1121, Japan \\ ${ }^{4}$ Institute of Multidisciplinary Research for Advanced Materials, Tohoku University, 2-1-1 Katahira, Aoba-ku, Sendai 980-8577, Japan \\ Corresponding author, Takashi NAKAMURA; E-mail: tnakamur@dent.osaka-u.ac.jp
}

\begin{abstract}
Yttria-based zirconia material (Y-TZP) widely used in dentistry, may degrade in a humid, low-temperature environment such as that in the oral cavity. The aim of this study was to compare the degradation of a new silica doped Y-TZP material with that of conventional Y-TZP by using accelerated aging tests at $200^{\circ} \mathrm{C}$. The results of the accelerated tests revealed that after 50 hours of aging, the conventional Y-TZP samples had damaged surfaces that were weakened by 50 to $60 \%$, while the silica-doped Y-TZP samples were only weakened by less than $20 \%$. The monoclinic content of the conventional Y-TZP samples increased substantially to $62.7 \%$, however, that of silica-doped Y-TZP samples was 18.9\% after 5 hours of aging. It was concluded that a new type of silica-doped Y-TZP, created by adding a small amount of silica to Y-TZP, will be more resistant to low temperature degradation than conventional Y-TZP.
\end{abstract}

Keywords: Zirconia, Silica, Degradation, Accelerated aging test

\section{INTRODUCTION}

All-ceramic restorations provide excellent esthetics and bio-compatibility. They recently have become increasingly popular because of the development of dental ceramics with superior physical properties and advances in the CAD/CAM systems available for fabricating restorations. Zirconia is one of the strongest and most fracture-resistant of the available dental ceramics, and it can only be fabricated for dental applications using a CAD/CAM system ${ }^{1,2)}$. Zirconia not only has excellent physical properties for the purpose, but also has some degree of translucence, making it suitable for the frame material of all-ceramic crowns and fixed partial dentures ${ }^{3,4)}$. Before zirconia was used for clinical applications, materials containing alumina or lithium disilicate were used for making fixed partial denture frames. However, these materials could not be used for the treatment of posterior teeth because they were not strong enough for that purpose ${ }^{5}$. Zirconia can be used for the frames of posterior fixed partial dentures, and recently has begun to be used for dental implants ${ }^{6,7)}$.

Yttria-stabilized tetragonal zirconia polycrystal (Y-TZP) is now widely used in dentistry. Y-TZP is very strong and fracture-resistant. However, it is known that the material can degrade in a humid, low-temperature environment ${ }^{8}$. Therefore, a Y-TZP restoration might degrade in the oral cavity after a long period of time, and possibly fracture. On the other hand, it is reported that adding a small amount of silica to Y-TZP can suppress this low temperature degradation (LTD) of zirconia ${ }^{9,10)}$. Doping zirconia with silica might make it possible to provide all-ceramic restorations that can survive in the oral cavity for a long period without fracturing.
A new type of zirconia material was created for testing during this study, by adding a small amount of silica to Y-TZP. Accelerated aging tests were then conducted on samples of the new type of zirconia and on conventional zirconia samples, and the results of testing both types of samples were compared in terms of changes in strength and crystalline structure. In addition, the appropriateness of this new type of zirconia doped with silica as dental ceramic materials was examined.

\section{MATERIALS AND METHODS}

Two types of zirconia powder were used as the bases of this study: commercially available Y-TZP containing 3 mol\% of yttria (Sample Z, $\mathrm{ZrO}_{2}+\mathrm{HfO}_{2}: 94.3 \mathrm{wt} \%, \mathrm{Y}_{2} \mathrm{O}_{3}$ : $5.4 \mathrm{wt} \%, \mathrm{Al}_{2} \mathrm{O}_{3}: 0.26 \mathrm{wt} \%, \mathrm{SiO}_{2}: 0.01 \mathrm{wt} \%$ ) (Tohso Co., Tokyo, Japan) and Y-TZP doped with $0.2 \mathrm{~mol} \%$ of $\mathrm{Si}$ (Sample $\mathrm{S}, \mathrm{ZrO}_{2}+\mathrm{HfO}_{2}: 93.94 \mathrm{wt} \%, \mathrm{Y}_{2} \mathrm{O}_{3}: 5.36 \mathrm{wt} \%, \mathrm{Al}_{2} \mathrm{O}_{3}$ : $\left.0.26 \mathrm{wt} \%, \mathrm{SiO}_{2}: 0.41 \mathrm{wt} \%\right)$. The two types of powder were sintered at $1,400^{\circ} \mathrm{C}, 1,450^{\circ} \mathrm{C}$, and $1,500^{\circ} \mathrm{C}$, and the resultant sintered compact of each type were cut into blocks measuring $20 \mathrm{~mm} \times 4 \mathrm{~mm} \times 1.2 \mathrm{~mm}$ (thickness) and polished with a \#800 diamond disc and then with a \#400 rotating grinding wheel to chamfer the edges, thus yielding the specimens. Fourteen specimens of each type were prepared and divided into control and aging test groups, seven in each group. The aging group specimens were immersed in distilled water inside a decomposition vessel consisting of an inner teflon tube and an outer stainless tube. They were all subjected to an accelerated aging test for 50 hours at $200^{\circ} \mathrm{C}$ and 2 atm using a drying oven (MOV-112, SANYO Electric Co., Osaka, Japan). The volume of water was provided to become $2 \mathrm{~atm}$ in the vessel. After the aging test, the specimens were subjected 
to a 3-point bending test according to ISO 6872, a standard for dental ceramic materials ${ }^{11)}$, and then their crystalline structure was evaluated by X-ray diffraction (XRD). The monoclinic content was calculated from the results of the XRD analysis, using the Garvie-Nicholson equation $^{12)}$.

In addition, change in the strength of each type was examined using specimens prepared by sintering types $\mathrm{Z}$ and $\mathrm{S}$ at $1,450^{\circ} \mathrm{C}$. They were subjected to accelerated aging tests for 5, 10 and 20, and 40 hours by being immersed in water at $200^{\circ} \mathrm{C}$ and $2 \mathrm{bar}$, and then subjected to a 3-point bending test. The monoclinic content at the surface of the each specimen versus aging time was evaluated and calculated by XRD. 28 specimens were prepared from each of types $\mathrm{Z}$ and $\mathrm{S}$ and seven specimens were subjected to each aging period. The fracture surface of specimens of types $\mathrm{S}$ and $\mathrm{Z}$ which had been subjected to 40 hours of accelerated aging was observed under a scanning electron microscope (SEM). Using the SEM pictures thus obtained, the thickness of the degraded layer was measured at a total of 60 points on each specimen and an average value was obtained. The statistical comparison of the test results between types $\mathrm{S}$ and $\mathrm{Z}$ was performed using Student's t-test, and the comparison of strengths across different aging times was performed using one-way ANOVA and Tukey's multiple comparison test.

Furthermore, the chemical solubility and radioactivity of types $\mathrm{Z}$ and $\mathrm{S}$ were measured according to ISO 6872, to examine their appropriateness as dental ceramic materials. To prepare specimens for the chemical solubility test, each sample was sintered at $1,450^{\circ} \mathrm{C}$ and cut into blocks measuring $40 \times 40 \times 10 \mathrm{~mm}$. The specimens thus prepared were immersed in a $4 \%$ acetic acid solution at $80^{\circ} \mathrm{C}$ for 16 hours to determine possible changes in weight. In the radioactivity test, the gamma-ray spectrum was obtained for each powder sample (50 g).

\section{RESULTS}

Before being subjected to the accelerated aging tests, each sample was subjected to a flexural strength test. Type $\mathrm{Z}$ demonstrated an average flexural strength of
1,010-1,050 MPa and Type S demonstrated an average flexural strength of 1,160-1,200 MPa. Type S exhibited significantly greater flexural strength than type $\mathrm{Z}$, across all sintering temperatures $\left(1,400^{\circ} \mathrm{C}, 1,450^{\circ} \mathrm{C}\right.$, or $\left.1,500^{\circ} \mathrm{C}\right)$ $(p<0.01)$ (Fig. 1$)$.

After 50 hours of accelerated aging, type Z's flexural strength dropped 50 to $60 \%$, to 380 to $520 \mathrm{MPa}$. However, the surfaces of the specimens prepared by sintering type $\mathrm{Z}$ at $1,400^{\circ} \mathrm{C}$ and $1,450^{\circ} \mathrm{C}$ were damaged during testing and thus the flexural strength values obtained should be regarded as reference values only. The specimens prepared by sintering type $\mathrm{Z}$ at $1,500^{\circ} \mathrm{C}$ broke into pieces during testing and therefore the flexural strength could not be determined (Fig. 2). On the other hand, all specimens of type $\mathrm{S}$ also exhibited reduced flexural strength after the accelerated aging test, regardless of the temperature used for sintering. However, specimens

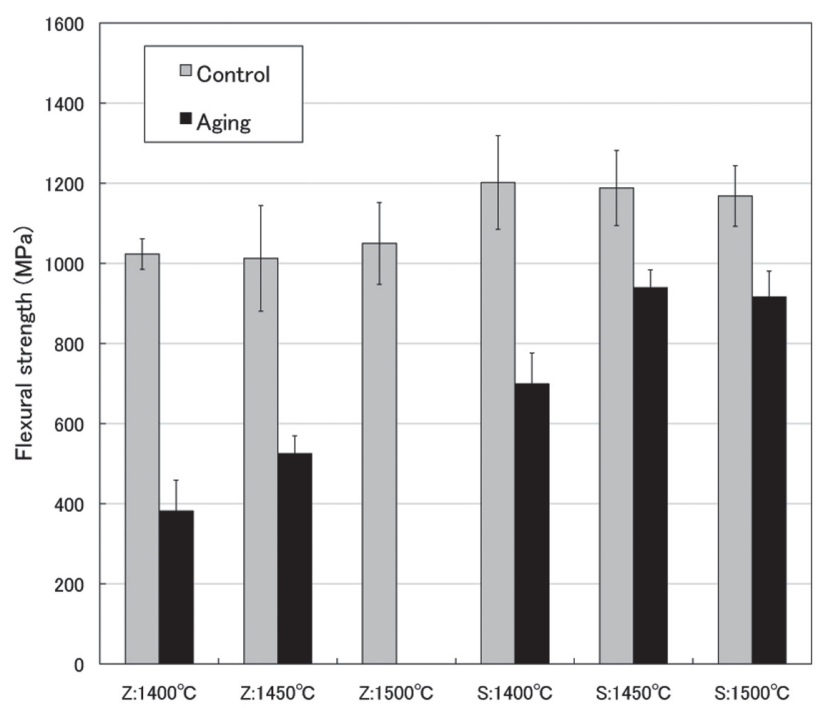

Fig. 1 Flexural strength subjected to 50 hours of aging. Specimens, prepared by sintering type $\mathrm{S}$ at $1,400^{\circ} \mathrm{C}$ and $1,500^{\circ} \mathrm{C}$, retained a strength of resistance to pressures of $950 \mathrm{MPa}$ or more and they were weakened by less than $20 \%$ after accelerated tests.
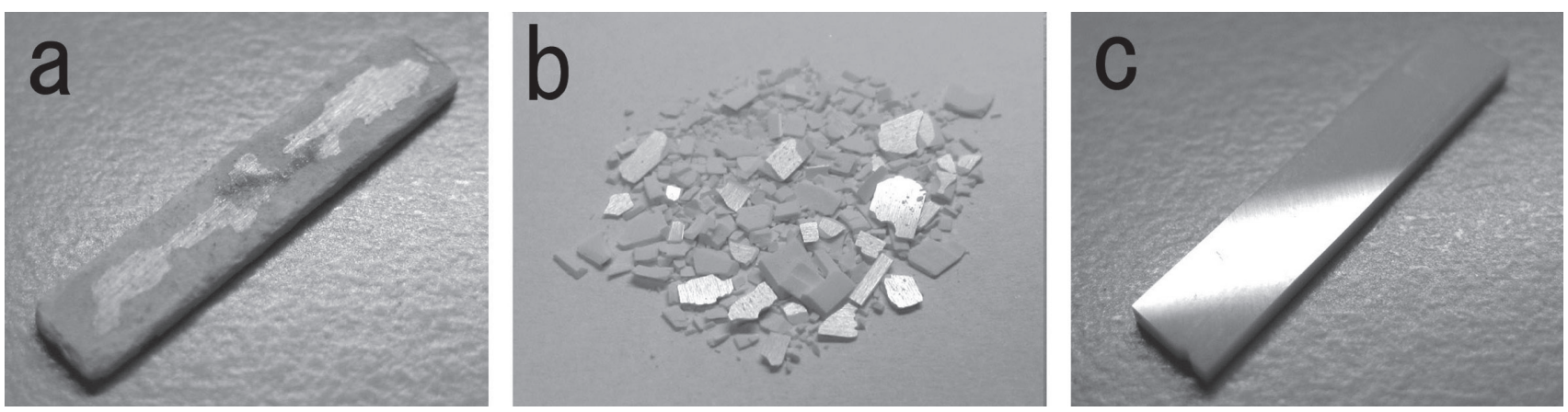

Fig. 2 Specimens subjected to 50 hours of aging. Specimens prepared by sintering type Z at $1,400^{\circ} \mathrm{C}$ and $1,450^{\circ} \mathrm{C}$ had surface damage (a). Those prepared by sintering type $\mathrm{Z}$ at $1,500^{\circ} \mathrm{C}$ broke into pieces during testing (b). Specimens prepared by sintering type $\mathrm{S}$ at $1,500^{\circ} \mathrm{C}$ did not show any change after 50 hours of aging (c). 
Table 1 The monoclinic content of specimens subjected to 50 hours of aging. Type $\mathrm{Z}$ specimens had higher monoclinic content than type $\mathrm{S}$

\begin{tabular}{ccc}
\hline & Control & Aging \\
\hline $\mathrm{Z}: 1,400^{\circ} \mathrm{C}$ & 8.53 & 82.30 \\
$\mathrm{Z}: 1,450^{\circ} \mathrm{C}$ & 8.66 & 78.47 \\
$\mathrm{Z}: 1,500^{\circ} \mathrm{C}$ & 8.71 & 70.31 \\
$\mathrm{~S}: 1,400^{\circ} \mathrm{C}$ & 5.33 & 81.46 \\
$\mathrm{~S}: 1,450^{\circ} \mathrm{C}$ & 7.45 & 47.88 \\
$\mathrm{~S}: 1,500^{\circ} \mathrm{C}$ & 9.42 & 55.92 \\
\hline
\end{tabular}

prepared by sintering type $\mathrm{S}$ at $1,450^{\circ} \mathrm{C}$ and $1,500^{\circ} \mathrm{C}$ retained a flexural strength of $950 \mathrm{MPa}$ or more, after the accelerated aging test, limiting their strength reduction to less than $20 \%$ (Fig.1). The result of XRD showed that the monoclinic content increased in both the types after the accelerated aging test. In the case of type $\mathrm{Z}$, the specimens prepared by sintering the sample at $1,450^{\circ} \mathrm{C}$, which had the highest flexural strength of the three types of specimen after the accelerated aging test, had a monoclinic content of $78 \%$, a value that was far higher than that obtained by the specimens of type S (47\%) prepared by sintering at $1,450^{\circ} \mathrm{C}$ (Table 1$)$.

Accelerated aging tests were performed for various lengths of time. Type $\mathrm{S}$ was stronger than type $\mathrm{Z}$ regardless of aging time, indicating a significant difference between the two types $(p<0.01)$ (Fig.3). There was no significant difference in the strength of type $\mathrm{S}$ when measured before testing and when measured after 5 hours, 10 hours and 20 hours of aging. Type $\mathrm{Z}$ also did not show any significant weakening when measured before testing and after 5 hours and 10 hours of aging, but it weakened significantly at aging times of 20 hours and more $(p<0.05)$. In addition, all the specimens were damaged when aged for 40 hours or more.

It was found that for both types $\mathrm{S}$ and $\mathrm{Z}$, the longer the aging time, the greater the monoclinic content (Fig.4). The monoclinic content of type $\mathrm{Z}$ increased substantially from $8.6 \%$ at the start of testing to $62.7 \%$ after 5 hours of aging, but changes were relatively small thereafter; that is, it increased to $67 \%$ after 10 hours and to $78 \%$ after 50 hours (Fig.5). The monoclinic content of type S gradually increased from $7.4 \%$ at the start of testing to $18.9 \%$ after 5 hours and to $32.1 \%$ after 10 hours. However, it did not change very much thereafter, increasing to $44.9 \%$ after 20 hours and to $47.8 \%$ after 50 hours. The fracture surfaces of specimens of types $\mathrm{S}$ and $\mathrm{Z}$ which had been subjected to 40 hours of accelerated aging were observed under a scanning electron microscope (SEM). The thickness of the degraded layer was $36.7 \mu \mathrm{m}$ on average for type $\mathrm{Z}$ and $12 \mu \mathrm{m}$ on the average for type $\mathrm{S}$ (Fig. 6).

The chemical solubility of types $\mathrm{S}$ and $\mathrm{Z}$ was examined. Both types experienced no reduction in weight, thus satisfying the ISO 6872 requirements (100

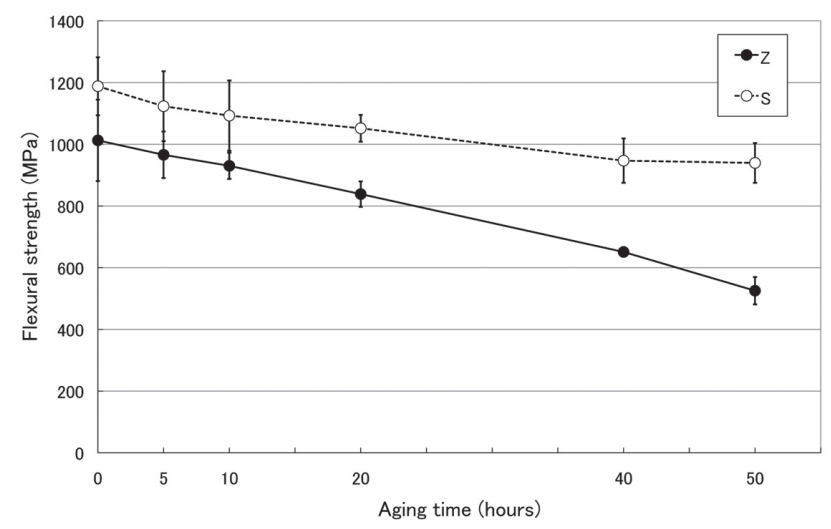

Fig. 3 The strength of specimens subjected to accelerated aging tests for different periods. When accelerated aging tests were conducted for 20 hours or longer, the type $\mathrm{Z}$ specimens were weakened greatly.

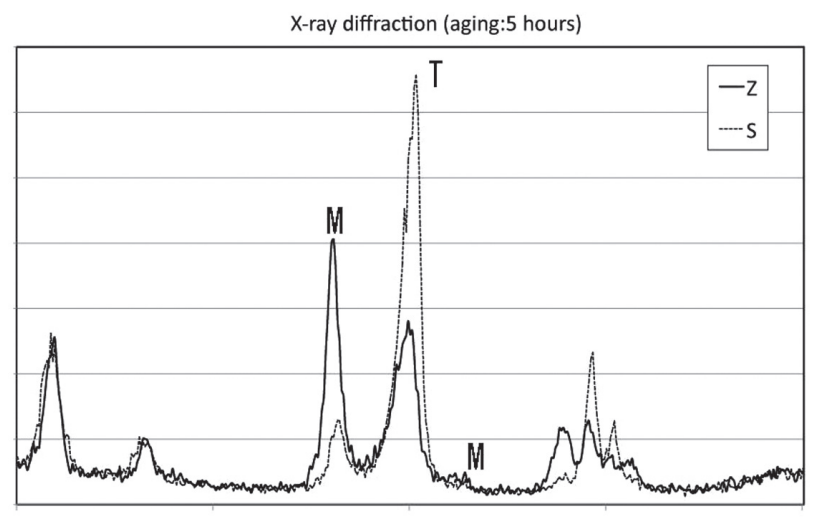

$\begin{array}{lllllllllllllllllllll}20 & 21 & 22 & 23 & 24 & 25 & 26 & 27 & 28 & 29 & 30 & 31 & 32 & 33 & 34 & 35 & 36 & 37 & 38 & 39 & 40\end{array}$ $2 \theta$ scale

Fig. 4 The result of an XRD analysis of specimens subjected to 5 hours of aging. Type Z specimens showed higher monoclinic content than type $\mathrm{S}$. (M: Monoclinic, T: Tetragonal)

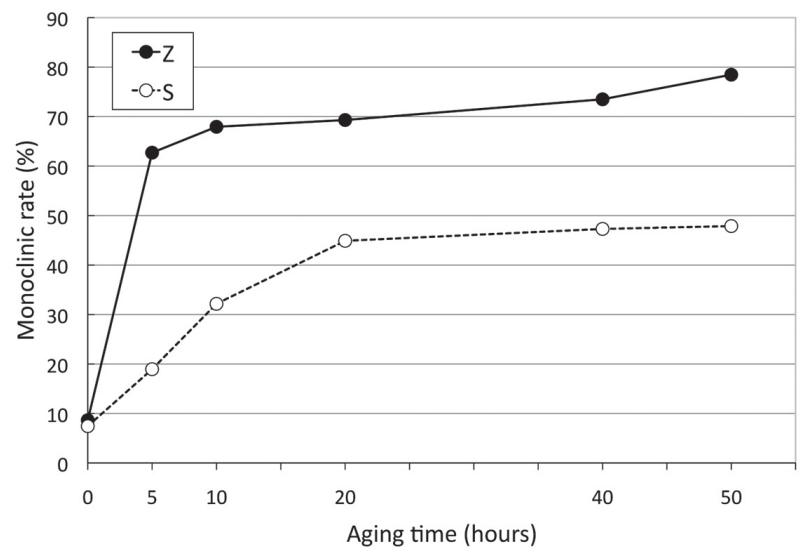

Fig. 5 The monoclinic content of specimens subjected to accelerated aging tests for different periods. Type $\mathrm{Z}$ specimens underwent a large increase in monoclinic content after 5 hours of aging. 

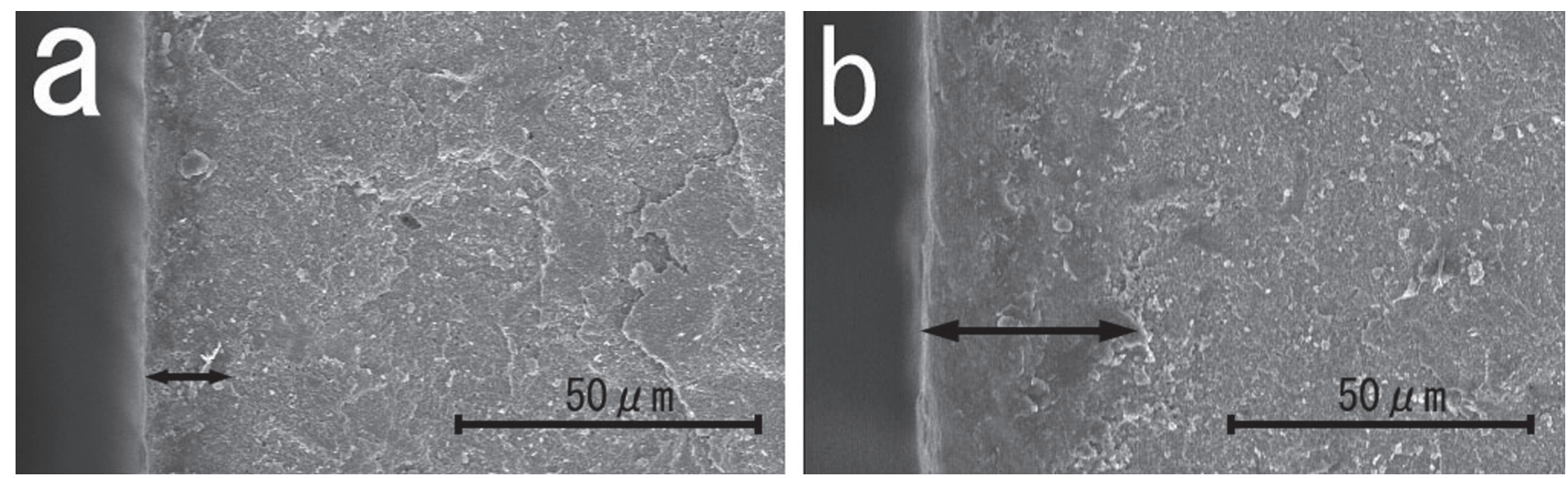

Fig. 6 SEM pictures of the fracture surface of specimens subjected to 40 hours of aging. Type S (a) had a shallower degradation layer than type $\mathrm{Z}(\mathrm{b})$.

$\mu \mathrm{g} / \mathrm{cm}^{2}$ or less). Both types also satisfied the ISO 6872 requirement for radioactivity $(1.0 \mathrm{~Bq} / \mathrm{g}$ or less).

\section{DISCUSSION}

Tetragonal zirconia polycrystal doped with $3 \mathrm{~mol} \%$ of yttria (Y-TZP) has been used extensively in dentistry. Its sintered compact consists almost entirely of tetragonal zirconia. Y-TZP has excellent chemical durability, but it is subject to degradation due to phase transformation in a humid atmosphere even in low ambient temperatures. It is thought that Y-TZP undergoes a phase transformation from a tetragonal to a monoclinic phase, accompanied by a volume increase of about $4 \%$ after it has been maintained for a certain period of time in the presence of water; the surface then roughens, causing cracks, thus resulting in degradation ${ }^{13)}$.

Y-TZP has been used as a biocompatible material for the heads of hip joint prostheses since the 1980's. However, it has been reported that zirconia femoral heads sometimes fractures in clinical use ${ }^{14)}$.

Y-TZP has also begun to be used to make the frames of crowns or fixed partial dentures and for implants, as well ${ }^{7}$. The use of Y-TZP frames makes it possible to fabricate fixed partial dentures for posterior as well as anterior teeth, so they have come to be used frequently where esthetics are paramount. The short-term prognosis for zirconia fixed partial dentures includes a strong possibility of chipped veneer porcelain, but the Y-TZP frame itself hardly ever fractures ${ }^{15,16)}$. However, Y-TZP degrades in a humid environment, even if the ambient temperature is low. It is said that a connector of the fixed partial denture is subjected to a tensile stress of a few hundred $\mathrm{MPa}$, which accelerates the degradation of the connector $^{17)}$. Therefore, considering that fixed partial dentures are intended to reside in the oral cavity for a long period of time, the zirconia material used to make the connector of the fixed partial denture needs to be highly resistant to degradation.

In this study, commercially-available zirconia powder was sintered to prepare a conventional Y-TZP sample. Y-TZP products used in actual clinical settings vary slightly in composition among different manufacturers, but it appears that the basic composition, such as the ratio of zirconia and yttria, is almost always the same. Our type S material was prepared by adding a small amount $(0.2 \mathrm{~mol} \%)$ of silica to pure Y-TZP. Our preliminary experiment confirmed that zirconia blocks, fabricated by sintering type $\mathrm{S}$ completely, could be milled by a $\mathrm{CAD} / \mathrm{CAM}$ system in the same way as commerciallyavailable dental Y-TZP blocks ${ }^{18)}$. Y-TZP is usually sintered within the range of $1,350^{\circ} \mathrm{C}$ to $1,550^{\circ} \mathrm{C}^{7}$, and thus in this study sample powders were sintered at three temperatures: $1,400^{\circ} \mathrm{C}, 1,450^{\circ} \mathrm{C}$, and $1,500^{\circ} \mathrm{C}$. Both types $\mathrm{S}$ and $\mathrm{Z}$ samples had a flexural strength of $1000 \mathrm{MPa}$ or more, indicating that they were equal in strength to commercially-available Y-TZP products ${ }^{3)}$. Type $\mathrm{S}$ had a flexural strength about $10 \%$ higher than type Z, probably because the former contained a small amount of silica.

An accelerated aging test of zirconia is usually conducted within the range of $120^{\circ} \mathrm{C}$ to $140^{\circ} \mathrm{C}$ using an autoclave on the assumption that the material will be used for artificial joints ${ }^{19,20)}$. Considering that the fluctuation in temperature within the oral cavity is greater than inside the extremities, our accelerated aging test was conducted under more severe conditions, using a water bath at $200^{\circ} \mathrm{C}$. After being subjected to accelerated aging for 50 hours in water at $200^{\circ} \mathrm{C}$, the type $\mathrm{S}$ specimens retained the same form they had before degradation, while the type $\mathrm{Z}$ specimens were so remarkably degraded that they even had a damaged appearance to the naked eye. In particular, the specimens prepared by sintering type $\mathrm{Z}$ at $1,500^{\circ} \mathrm{C}$ broke into pieces during testing due to degradation. Type $\mathrm{S}$ specimens prepared by sintering at $1,400^{\circ} \mathrm{C}$ tested as the weakest samples of that type. It was found the material was stronger when sintered at $1,450^{\circ} \mathrm{C}$ to $1,500^{\circ} \mathrm{C}$. The monoclinic content, an index for the degree of degradation, was 78 to $82 \%$ for the type $\mathrm{Z}$ specimens, except for those that broke into pieces. It has been reported that the monoclinic content of Y-TZP was found to be $81 \%$ after an accelerated aging test conducted for 190 hours at $121^{\circ} \mathrm{C}^{19)}$ and $80 \%$ for 12 hours at $134^{\circ} \mathrm{C}^{20)}$. Those values were almost the same as those obtained for 
our type $\mathrm{Z}$ specimens after an accelerated aging test conducted for 50 hours at $200^{\circ} \mathrm{C}$. Once a certain level of degradation occurs, the monoclinic content does not change regardless of aging temperature or time. This is probably because after degradation causes the monoclinic content to reach around $75 \%$ there is a plateau ${ }^{10)}$, and no further degradation will occur, even with further aging.

On the other hand, the specimens prepared by sintering type $\mathrm{S}$ at $1,450^{\circ} \mathrm{C}$ had the lowest monoclinic content, at $47 \%$, suggesting that this type has far higher resistance to degradation than type $\mathrm{Z}$. However, the specimens prepared by sintering type $\mathrm{S}$ at $1,400^{\circ} \mathrm{C}$ had a monoclinic content of $81 \%$ and were weak; thus it seems that the sintering temperature is also important to understanding zirconia's degradation history.

The strength and monoclinic content results obtained in our first experiment led us to conclude that specimens of types $\mathrm{Z}$ and $\mathrm{S}$ prepared by sintering at $1,450^{\circ} \mathrm{C}$ are highly resistant to degradation. Therefore, using specimens prepared by sintering at $1,450^{\circ} \mathrm{C}$, types $\mathrm{Z}$ and $\mathrm{S}$ were subjected to accelerated aging tests conducted over different aging periods. As the aging period was longer, the specimens of both types $\mathrm{Z}$ and $\mathrm{S}$ tended to become weaker. However, aging times of less than 20 hours for type S, and less than 10 hours for type $\mathrm{Z}$, did not cause significant differences in strength from those measured at the start of testing. As in this study, previous studies also have reported that the strength of zirconia does not change much during short periods of aging $^{21,22)}$. As for Y-TZP, it is reported that the strength might sometime rise even if the number of monoclinic increases by cutting or sand blasting ${ }^{23)}$. Therefore, it was guessed that there was a situation that the strength did not significantly decrease though the number of monoclinic increased in the early stages of degradation.

After 5 hours of aging, the type $\mathrm{Z}$ specimens had a monoclinic content of as much as $62.7 \%$, suggesting that the material had degraded rapidly. The latest version of an ISO standard (ISO 13356:2008) ${ }^{24)}$ concerning implants for surgery using ceramic materials based on Y-TZP imposes the criterion that a maximum of $25 \%$ of monoclinic material is present after an accelerated aging test conducted for 5 hours at $134^{\circ} \mathrm{C}$ and 2 bar. In our study, the type $\mathrm{S}$ specimens were subjected to an accelerated aging test for 5 hours at $200^{\circ} \mathrm{C}$, a higher temperature than the $134^{\circ} \mathrm{C}$ specified in the standard. It had a monoclinic content of $18.9 \%$ after testing was complete, thus indicating that the material sufficiently meets implant requirements. However, type $\mathrm{Z}$, a conventional Y-TZP, seems from our results to have insufficient strength to serve as an implant material.

Specimens of types $\mathrm{Z}$ and $\mathrm{S}$ subjected to 40 hours of aging were observed with SEM. The thickness of the degraded layer was $36 \mu \mathrm{m}$ for type $\mathrm{Z}$ and $12 \mu \mathrm{m}$ for type $\mathrm{S}$, indicating that type $\mathrm{S}$ had far higher resistance to degradation than the conventional Y-TZP.

It has been reported that the addition of a small amount of silica $(0.5 \mathrm{wt} \%)$ to Y-TZP decreases the internal stress by the presence of rounded grains, which improves its resistance to LTD without affecting its resistance to crack propagation ${ }^{10)}$. Specimens of type $\mathrm{S}$ used in this study had a silica content of $0.4 \mathrm{wt} \%$ and also had good resistance to LTD. On the other hand, it appears that degradation of Y-TZP is triggered by water penetrating into the grain boundaries of the zirconia ${ }^{25)}$. It was thought that the presence of silica in type $\mathrm{S}$ at the grain boundaries of the zirconia may prevent the penetration of water, suppressing the occurrence of degradation.

An alumina/ceria-based zirconia composite is used in dental clinical practice and is seen as a material with a good resistance to $\mathrm{LTD}^{26)}$. This material offers a higher resistance to fracture than conventional Y-TZP and it does not degrade easily. However, this composite material contains so much fine-grained alumina that it transmits almost no light, thus making it unattractive for use where esthetics is paramount.

The silica-doped zirconia used in this study has an excellent resistance against abrasion ${ }^{27)}$, while this material has almost same composition as conventional Y-TZP except for the small amount of doped silica. In addition, this silica-doped zirconia satisfies the requirements of chemical solubility and radioactivity imposed by ISO 6872, a dental ceramics standard. Therefore, it was thought that new silica-doped zirconia material might become useful for clinical dentistry, in view of the resistance to degradation that zirconia is known to exhibit.

\section{CONCLUSIONS}

A new type of zirconia doped with a small amount of silica was examined in this study. It was found after accelerated aging tests to develop less monoclinic content, have good resistance to degradation, and undergo only a small reduction in strength, as compared with conventional Y-TZP. In addition, it seemed likely that this material is appropriate for use as a dental ceramic.

\section{ACKNOWLEDGMENTS}

This study was supported in part by a Grant-in Aid for Scientific Research (No. 205922620) from the Ministry of Education, Culture, Sports, Science and Technology in Japan.

\section{REFERENCES}

1) Koutayas SO, Vagkopoulou T, Pelekanos S, Koidis P, Strub JR. Zirconia in dentistry: part 2. Evidence-based clinical breakthrough. Eur J Esthet Dent 2009; 4: 348-380.

2) Kokubo Y, Tsumita M, Kano T, Sakurai S, Fukushima S. Cinical marginal and internal gaps of zirconia all-ceramic crowns. J Prosthodont Res 2011; 55: 40-43.

3) Guazzato M, Albakry M, Ringer SP, Swain MV. Strength, fracture toughness and microstructure of a selection of all-ceramic materials. Part 2. Zirconia-based dental ceramics. Dent Mater 2004; 20: 449-456.

4) Yoshida A, Miller L, Da Silva JD, Ishikawa-Nagai S. Spectrophotometric analysis tooth color reproduction on 
anterior all-ceramic crowns: part 2: color reproduction and its transfer from in vitro to in vivo. J Esthet Restor Dent 2010; 22: 53-63.

5) Tinschert J, Natt G, Mautsh W, Augthun M, Spiekermann H. Fracture resistance of lithium disilicate-, alumina-, and zirconia-based three-unit fixed partial dentures: a laboratory study. Int J Prosthodont 2001; 14: 231-238.

6) Kohal RJ, Klaus G, Strub JR. Zirconia-implant-supported all-ceramic crowns withstand long-term load: a pilot investigation. Clin Oral Implants Res 2006; 17: 565-571.

7) Denry I, Kelly JR. State of the art of zirconia for dental applications. Dent Mater 2008; 24: 299-307.

8) Lawson S. Environmental degradation of zirconia ceramics. J Eur Ceram Soc 1995; 15: 485-502.

9) Gremillard L, Epicier T, Chevalier J, Fantozzi G. Microstructural study of silica-doped zieconia ceramics. Acta Materialla 2000; 48: 4647-4652.

10) Gremillard L, Chevalier J, Fantozzi G, Epicier T. Improving the durability of a biomedical grade Zirconia ceramic by addition of Silica. J Am Ceram Soc 2002; 85: 401-405.

11) International Standard Organization No.6872. DentistryCeramic materials. Geneva: International Organization for Standardization; 2008.

12) Garvie RC, Nicholson PS. Phase analysis in zirconia systems. J Am Ceram Soc 1972; 55: 303-305.

13) Chevalier J. What future for zirconia as a biomaterial? Biomaterials 2006; 27: 535-543.

14) Piconi C, Maccauro G, Angeioni M, Rossi B, Leamonth ID. Zirconia heads in perspective: a survey of zirconia outcomes in total hip replacement. Hip Int 2007; 17: 119-130.

15) Sailer I, Feher A, Filser F, Gauckler LJ, Hammerle CH. Five-year clinical results of zirconia frameworks for posterior fixed partial dentures. Int J Prosthodont 2007; 20: 383-388.

16) Roediger M, Gersdorff N, Huels A, Rinke S. Prospective evaluation of zirconia posterior fixed partial dentures: four-year clinical results. Int J Prosthodont 2010; 23: 141-148.

17) Lughi V, Sergo V. Low temperature degradation -aging- of zirconia: A critical review of the relevant aspects in dentistry.
Dent Mater 2010; 26: 807-820.

18) Usami H, Nakamura T, Nishia H, Wakabayashi K, Yatani $H$. Influence of silica addition to Y-TZP on mechanical property. J J Dent Mater 2010; 29: 113.

19) Tanaka K, Tamura J, Kawanabe K, Nawa M, Uchida M, Kokubo T, Nakamura T. Phase stability after aging and its influence on pin-on disk wear properties of Ce-TZP/Al $\mathrm{O}_{3}$ nanocomposite and conventional Y-TZP. J Biomed Mater Res A 2003; 67: 200-207.

20) Deville S, Gremillard L, Chevalier J, Fantozzi G. Critical comparison of methods for the determination of the aging sensitivity in biomedical grade yttria-stabilized zirconia. J Biomed Mater Res A 2005; 72: 239-245.

21) Ardlin BL. Transformation-toughened zirconia for dental inlays, crowns and bridges: chemical stability and effect of low-temperature aging on flexural strength and surface structure. Dent Mater 2002; 18: 590-595.

22) Papanagiotou HP, Morgano SM, Giordano RA, Pober R. In vitro evaluation of low-temperature aging effects and finishing procedures on the flexural strength and structural stability of Y-TZP dental ceramics. J Prosthet Dent 2006; 96: 154-164

23) Kosmac T, Dakskobler A, Oblak C, Jevnikar P. The strength and hydrothermal stability of Y-TZP ceramics for dental application. Int J Appl Ceram Technol 2007; 4: 164-174.

24) International Standard Organization No.13356. Implants for surgery -Ceramic materials based on yttria-stabilized tetragonal zirconia (Y-TZP), 2008.

25) Guo X, Schober T. Water incorporation in tetragonal zirconia. J Am Ceram Soc 2004; 87: 746-748.

26) Ban S, Nawa M, Suehiro Y, Nakanishi H. Mechanical properties of zirconia/alumina nano-composite after soaking in various water-based condition. Key Engin Mater 2006; 309-311: 1219-1222.

27) Ohnishi H, Takeuchi M, Sekino T, Ikuhara Y, Niihara K. Wear resistance of $\mathrm{SiO}_{2}$-doped Y-TZP grinding media during wet milling. Int J Appl Ceram Technol 2010; 7: 502-511. 